\title{
Internal Resorption Management Using Hybrid Irrigation with bioceramics: A Report of Three Cases
}

Mohammad Yaman Seirawan ${ }^{1}$, Mohammad Kinan Seirawan $^{2}$, and Mazen Doumani²

${ }^{1}$ Faculty of Dentistry, University of Damascus, Damascus, Syria.

${ }^{2}$ Vision College of Dentistry and Nursing, Riyadh, Saudi Arabia.

September 17, 2021

\begin{abstract}
Three-dimensional sealing and disinfecting is a very difficult challenge in the canals affected by internal resorption. Hybrid irrigation is a method that takes advantage of both ultrasonic / sonic activations, which has previously proven effective in cleaning the root canals. Also, modern biological materials are suitable to seal these canals.
\end{abstract}

\section{Hosted file}

Internal Resorption Management Using Hybrid Irrigation with biomaterial fillers.docx available at https://authorea.com/users/434107/articles/537432-internal-resorption-managementusing-hybrid-irrigation-with-bioceramics-a-report-of-three-cases
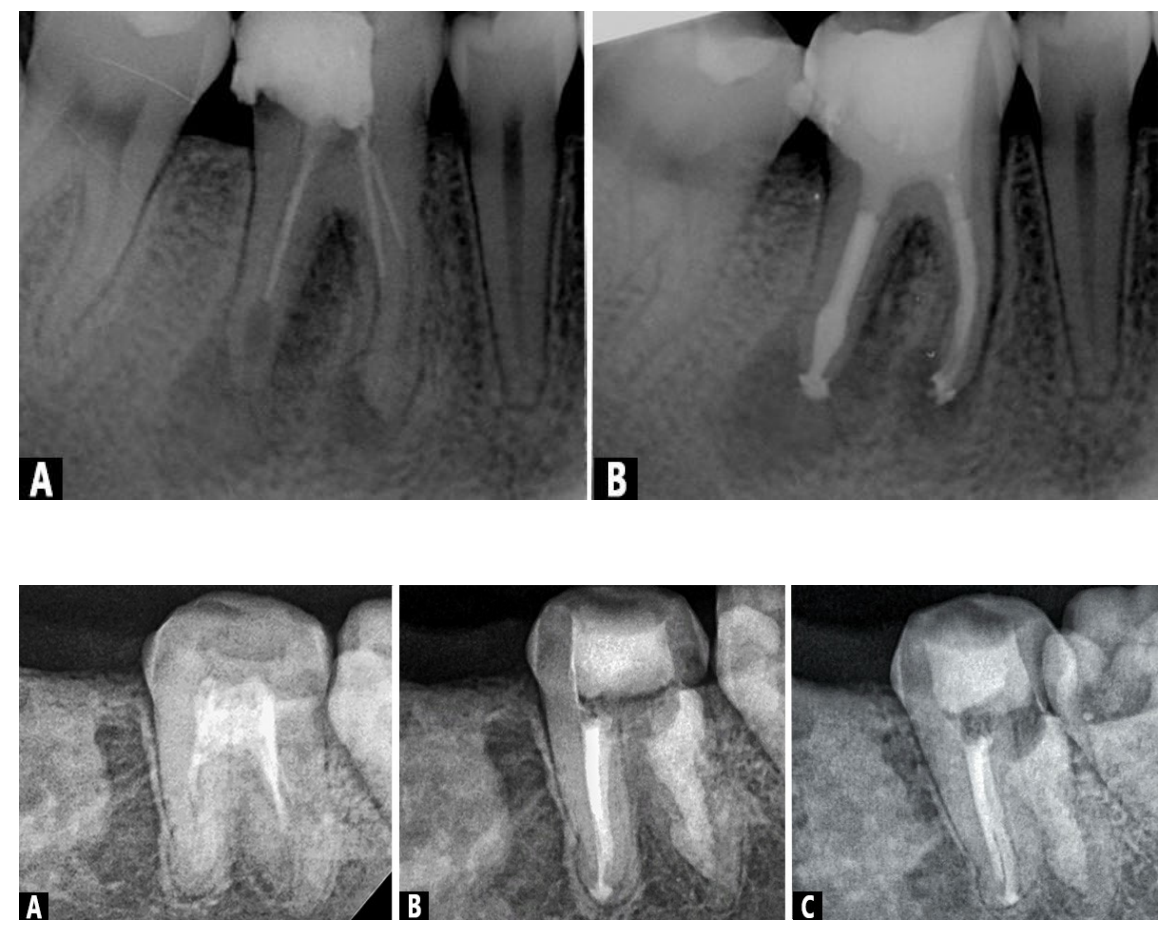


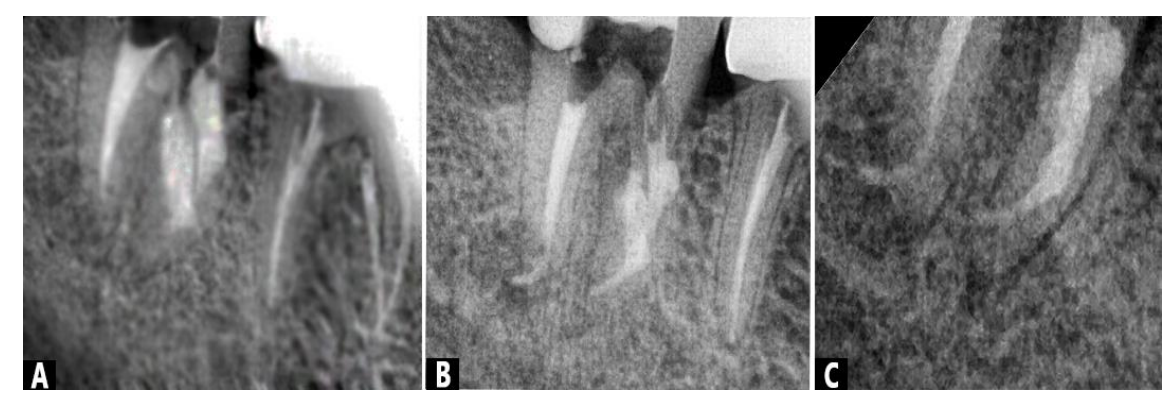

